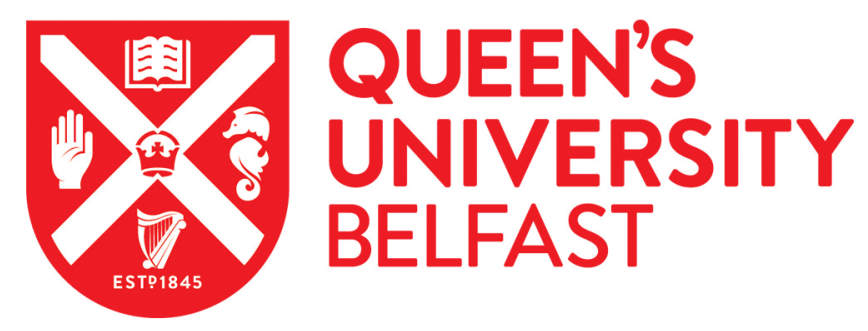

\title{
Enhancing the electrical conductivity of carbon fibre thin-ply laminates with directly grown aligned carbon nanotubes
}

\author{
Russello, M., Diamanti, E. K., Catalanotti, G., Ohlsson, F., Hawkins, S. C., \& Falzon, B. G. (2018). Enhancing \\ the electrical conductivity of carbon fibre thin-ply laminates with directly grown aligned carbon nanotubes. \\ Composite Structures, 206, 272-278. https://doi.org/10.1016/j.compstruct.2018.08.040
}

Published in:

Composite Structures

Document Version:

Peer reviewed version

Queen's University Belfast - Research Portal:

Link to publication record in Queen's University Belfast Research Portal

\section{Publisher rights}

Copyright 2018 Elsevier.

This manuscript is distributed under a Creative Commons Attribution-NonCommercial-NoDerivs License

(https://creativecommons.org/licenses/by-nc-nd/4.0/), which permits distribution and reproduction for non-commercial purposes, provided the author and source are cited.

\section{General rights}

Copyright for the publications made accessible via the Queen's University Belfast Research Portal is retained by the author(s) and / or other copyright owners and it is a condition of accessing these publications that users recognise and abide by the legal requirements associated with these rights.

Take down policy

The Research Portal is Queen's institutional repository that provides access to Queen's research output. Every effort has been made to ensure that content in the Research Portal does not infringe any person's rights, or applicable UK laws. If you discover content in the Research Portal that you believe breaches copyright or violates any law, please contact openaccess@qub.ac.uk. 


\section{Accepted Manuscript}

Enhancing the electrical conductivity of carbon fibre thin-ply laminates with directly grown aligned carbon nanotubes

M. Russello, E.K. Diamanti, G. Catalanotti, F. Ohlsson, S.C. Hawkins, B.G. Falzon

PII: S0263-8223(18)31747-1

DOI: https://doi.org/10.1016/j.compstruct.2018.08.040

Reference: COST 10090

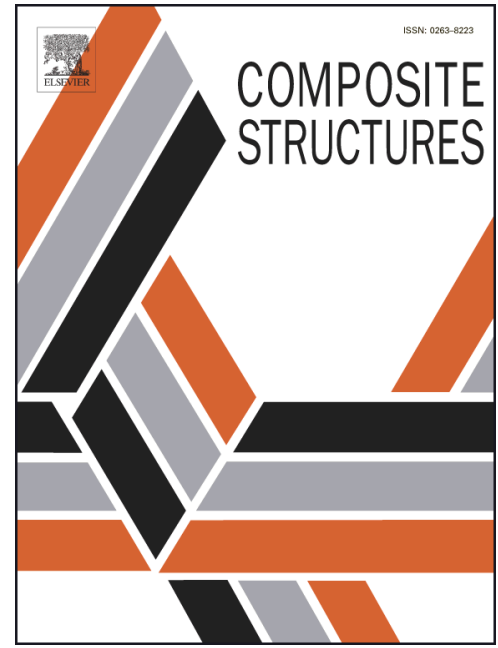

To appear in:

Composite Structures

Please cite this article as: Russello, M., Diamanti, E.K., Catalanotti, G., Ohlsson, F., Hawkins, S.C., Falzon, B.G., Enhancing the electrical conductivity of carbon fibre thin-ply laminates with directly grown aligned carbon nanotubes, Composite Structures (2018), doi: https://doi.org/10.1016/j.compstruct.2018.08.040

This is a PDF file of an unedited manuscript that has been accepted for publication. As a service to our customers we are providing this early version of the manuscript. The manuscript will undergo copyediting, typesetting, and review of the resulting proof before it is published in its final form. Please note that during the production process errors may be discovered which could affect the content, and all legal disclaimers that apply to the journal pertain. 


\title{
Enhancing the electrical conductivity of carbon fibre thin-ply laminates with directly grown aligned carbon nanotubes
}

\author{
M. Russello ${ }^{\mathrm{a}}$, E.K. Diamanti ${ }^{\mathrm{a}}$, G. Catalanotti ${ }^{\mathrm{a}, *}$, F. Ohlsson ${ }^{\mathrm{b}}$, S.C. Hawkins ${ }^{\mathrm{a}, \mathrm{c}}$, \\ B.G. Falzon ${ }^{a}$ \\ ${ }^{a}$ Advanced Composites Research Group (ACRG), School of Mechanical and Aerospace \\ Engineering, Queen's University Belfast, Belfast BT9 5AH, UK \\ ${ }^{b}$ Oxeon AB, Företagsgatan 24, Borås, Sweden \\ ${ }^{c}$ Department of Material Science and Engineering, Monash University, Clayton, Victoria \\ 3800, Australia
}

\begin{abstract}
The transverse electrical conductivity of thin-ply carbon fibre laminates, enhanced with carbon nanotubes (CNTs), was investigated experimentally. CNTs were directly synthesised on spread tow tapes of UTS50S carbon fibre through chemical vapour deposition (CVD). Unidirectional laminates were manufactured using both a thermosetting (epoxy) and a thermoplastic resin (polypropylene). A substantial increase in the electrical conductivity and a decrease in electrical anisotropy was observed for both the material systems investigated. Improvement in conductivity by a factor of 8 for the epoxy specimens, and 28 for the polypropylene specimens were reported.

Keywords: Carbon nanotubes, Thin-ply laminates, Electrical properties, Chemical vapour deposition (CVD)
\end{abstract}

\section{Introduction}

A renewed interest in the influence of ply thickness on the structural response of composite laminates, has been facilitated with the recent emergence of thinply laminates. Thin-plies are obtained through a technique which spreads fibre

\footnotetext{
* Corresponding author

Email address: G.Catalanotti@qub.ac.uk (G. Catalanotti)
} 
tows to thin and flat unidirectional tapes (Spread Tow Tape, STT) and fabrics (Spread Tow Fabric, STF) with a thickness that can be as low as $15 \mu \mathrm{m}$ (practically two or three fibre diameters through the thickness). It has been established that thin-ply laminates are characterized by a more uniform fibre distribution and, consequently, by the absence of matrix-rich areas. This has the positive effect of suppressing subcritical matrix damage [1, 2, 3, and improving the mechanical properties of those materials in terms of first-ply failure, fatigue life and ultimate strength. In particular, thin-ply laminates exhibit superior unnotched strength in both tension and compression [1, 2, 3, 4, 5, and better fatigue resistance [1, 2, 3, 5. On the other hand, the delay of matrix damage hinders the stress redistribution around holes or notches and consequently limits their notched resistance (because significant crack blunting does not occur). This, however, may be mitigated by designing the laminate so as to trigger specific damage mechanisms that will results in an improved notched strength 6 .

In addition to improved strength, the more uniform fibre distribution and the reduced ply thickness have the potential to influence other important physical properties, such as electrical and thermal conductivity. This would facilitate the introduction of multifunctionality in carbon fibre reinforced polymer (CFRP) composites.

It is well established that although carbon fibres are moderately conductive, their composites with non-conductive matrices are significantly less so. Thus the in-plane electrical conductivity of a unidirectional (UD) CFRP, in the fibre direction, is at least three orders of magnitude less than aluminium $\left(10^{7} \mathrm{~S} / \mathrm{m}\right)[7]$ and five orders of magnitude less in the transverse direction (between 0.1 and $10^{2} \mathrm{~S} / \mathrm{m}$ ). Consequently, to improve the Lightning Strike Protection (LSP) and Electromagnetic Compatibility (EMC) of aeronautical composite structures, airframers have had to resort to expanded metal foils and meshes, with the consequent increase in parasitic weight, manufacturing costs and maintenance.

Much effort has been expended by the research community to develop a viable conductive CFRP laminate which will eliminate the need for metallic meshes. One approach is to introduce carbon nanotubes (CNTs) into the CFRP, 
at a level well above the percolation threshold, to substantially increase the electrical conductivity of the composite [8, 9]. Essentially two ways exist to add CNTs to CFRP laminates: the first consists in infusing the carbon fibre with a CNT-loaded resin, the second in coating the fibre with CNTs.

The first method presents difficulties because the viscosity of the resin increases substantially when loaded with CNTs [10, 11] and therefore only low concentrations $(\leq 2 \mathrm{wt} \%)$ of CNTs can be used. Moreover, because CNTs of any significant aspect ratio tend to filter out onto the carbon fibres (CF) and hence fail to penetrate the structure, a uniform distribution of CNTs is difficult to achieve [12].

In the second approach, CNTs may be attached to the fibre by various techniques such as chemical grafting [13, 14, 15], electrophoretic deposition [16, [17, 18], fibre sizing [19], and direct syntheses onto the fibre surface, using, for example, chemical vapour deposition (CVD) 9, 20, 21, 22. An improvement in electrical conductivity was found by numerous research groups [23, 24, 25, 26. 27 .

CNT growth on CF has focused on the use of conventional tows and fabrics (hereinafter denoted as thick-ply laminates). Thin-ply CF offers several advantages over this approach in that it intrinsically enables uniform and facile penetration of catalyst and CVD reactants and growth of CNTs; it retains the scope of thin-ply advantages with respect to thick-ply; and it enables the creation of a truly hierarchical structure comprising CNT/thin-ply/thick-ply elements. In addition to the mechanical properties of the composite, this is also anticipated to improve the overall electrical conductivity, given that it is conceivable that the zone of highest resistance will be between the thick-plies.

The thin-ply approach enables the focus to remain on the thick-ply interlaminar region and the targeted and optimised enhancement of this rather than necessitating the CVD processing of the entire CF structure. Moreover, structures comprising only CNT-enhanced thin-ply are themselves anticipated to have remarkable mechanical and electrical properties. This could for example be applied to the outer surface of the airframe to enhance lightning strike 
protection.

In this paper we report a study of the production and electrical properties of CNT-enhanced thin-ply carbon fibre. CNTs were synthesised on UTS50S carbon fibre, and UD laminates were manufactured using both a thermosetting and a thermoplastic resin. Significant increases in transverse electrical conductivity were recorded.

\section{Materials and methods}

\subsection{Sizing removal and catalyst application}

Spread tow tapes of UTS50S carbon fibre, supplied by TeXtreme, were used in this investigation. The tapes had an areal weight of $32 \mathrm{~g} / \mathrm{m}^{2}$ and a width of $25 \mathrm{~mm}$; the fibres were kept together with a polymeric binder thread that had to be removed, together with the fibre sizing, before the actual coating, in order to avoid contamination of the CVD reactor. Removing the sizing and the binder requires considerable care as the fibres will tend to lose their original position, jeopardising the quality of the manufactured laminate. It is therefore essential to minimize the manipulation of the tape and to keep the fibres in position during all the necessary steps that are needed before the CVD.

A solvent approach (acetone) was tested for removal of the sizing, however the disruption to the alignment caused by the solvent surface tension was unacceptable. Moreover, the deposition of catalyst and CNT growth was found to be less uniform. Direct pyrolysis and evaporation of the binder and sizing, however, was found to be both quick and effective, and to facilitate uniform catalyst treatment. Portions of the carbon tape, with a length of $100 \mathrm{~mm}$, were cut from a supplied roll and placed on a curved plate (Figure 1). The thin-ply ribbon was kept in place using Kapton tape, and heated in air at $360{ }^{\circ} \mathrm{C}$ for 60 minutes.

[Figure 1 about here.]

After pyrolysis, a catalyst solution (iron(III) nitrate nonahydrate in isopropanol) was applied liberally, by pipette, to the top of the curved plate, which 
wetted the tape by capillary action. The plate's curvature ensured the stability of the tape while excess catalyst drained under gravity.

Trials were conducted to find the optimum parameters for a uniform and dense growth of CNTs, including catalyst concentration, age of the catalyst, time between two consecutive applications, and number of applications. It was found that the best result was obtained, by applying the catalyst, with a concentration of $0.2 \mathrm{~mol} / \mathrm{l}$, at intervals of 3.5 minutes, and repeating the process five times. Finally each sample was dried at room temperature for 15 hours and then at $95{ }^{\circ} \mathrm{C}$ for 3 hours.

\section{2. $C V D$ process}

After drying, each thin-ply sample was removed carefully from the curved plate, placed on a quartz glass slide and positioned in the centre of a quartz glass CVD reactor (42 $\mathrm{mm} \mathrm{ID)} \mathrm{within} \mathrm{a} 600 \mathrm{~mm}$ three zone split tube furnace.

After closure, the reactor was flushed with argon $(1 \mathrm{slm})$ for 10 minutes then heating commenced (ambient to $700{ }^{\circ} \mathrm{C}$ in 15 minutes followed by a dwell time of $5 \mathrm{~min})$. The argon was stopped and helium (1 slm) commenced (2 min) followed by a mixture of helium (960 sccm) plus hydrogen and acetylene (each 20 sccm) 28]. At the end of the reaction time, hydrogen and acetylene were halted and helium flow continued $(1 \mathrm{slm})$ for 5 minutes. The carrier gas was switched back to argon $(1 \mathrm{slm})$ and the reactor rapidly cooled to room temperature. The CVD process conditions were varied in order to determine the optimum reaction time which was found to range between 10 and $15 \mathrm{~min}$.

It was noted that a reaction time over $13 \mathrm{~min}$, lead to rapid CNT growth rate. Beyond 15 min, bundles of very long CNTs appear, as patches of growth break away from the $\mathrm{CF}$ and start growing independently (Figure 2). The pattern of growth seen on the CF is typical of dense CNT forests seen on cylinders. The CNT tips attach to one another by van der Waals interactions soon after growth commences. As growth continues, the increasing circumference of the tip zone puts the connection under tension until it splits into a series of narrow radial forest zones. Growth remains uniform around the fibre circumference but CNTs 
are directed into the zones from then on. If the CNT growth is excessive, the structure of the thin-ply fibre tape becomes distorted and unsuitable for manufacturing composite laminates without compromising their quality. Therefore, the reaction time is not recommended to exceed $13 \mathrm{~min}$.

[Figure 2 about here.]

\subsection{Specimen manufacture}

Thin-ply UD laminates with a $[0]_{2}$ layup were manufactured either by infusion with a thermosetting epoxy resin (IN2 / A30 slow hardener from Easy Composites Ltd) or by press moulding a thermoplastic film (Polypropylene (PP) produced by the Polymer Processing Research Centre (PPRC) at Queens University Belfast).

In order to understand the effect of both the thermal treatment and the presence of CNTs, on the electrical conductivity, laminates were manufactured using pristine thin-ply carbon fibres (UTS50S), thin-ply after pyrolysis of the sizing (UTS50SPy), and thin-ply with directly grown CNTs (UTS50S/CNTs).

To facilitate the infusion of the fibre with CNTs, IN2 resin with slow hardener (100:30) was diluted in acetone in proportion of $50 \mathrm{wt} \%$ in order to reduce its viscosity and increase the wettability of the fibres. After acetone evaporation (10 minutes at $25^{\circ} \mathrm{C}$ ), a fast cure was carried out in an oven at $100{ }^{\circ} \mathrm{C}$ for 3 hours. For PP, the laminate was manufactured by interleaving two thin-ply tapes with three PP films (each with a thickness of $50 \mu \mathrm{m}$ ) and moulding the preform in a Collin p200p hot press at $165{ }^{\circ} \mathrm{C}$ for 10 minutes using only the closing pressure of the press with zero nominal loading pressure. SEM analyses of the transverse cross section of the UTS50S/CNT/IN2 and UTS50S/CNT/PP laminates (Figures 34 do not reveal the presence of significant porosity within the laminate, suggesting that the resin infused correctly into the CNTs.

[Figure 3 about here.]

[Figure 4 about here.] 
Copper foil electrodes (Alfa Aeser, $25 \mu \mathrm{m}$ thick, 99.8\% Cu) were inserted during lamination to act as electrical contacts (Figure 5).

[Figure 5 about here.]

\subsection{Characterization and calculations}

A Hitachi FlexSEM 1000 Scanning Electron Microscope was used to observe the morphology of CNTs.

The transverse electrical resistance of the samples was measured using a 2 probe KEITHLEY 2000 multimeter. The 2 point probe (2PP) method using large-area electrodes placed with accurate alignment and spacing was used in preference to the 4 point probe ( $4 \mathrm{PP}$ ) method for the measurement of resistance. This approach was taken as the highly anisotropic nature of the specimens risks that a slight misalignment of a linear $4 \mathrm{PP}$ head with respect to the fibre (itself not always perfectly straight) would cause a significant change in the measurement; and the specimen surface had resin on it which varied from point to point, making it difficult to ensure that all 4 points of the $4 \mathrm{PP}$ are equally contacted, a problem obviated by the insertion of area electrodes during fabrication. Prior to this approach, a great deal of effort was expended to develop a methodology for removing the resin sufficiently without damaging the specimen structure. Finally, the 4 wire or $4 \mathrm{PP}$ approach is necessary where contact resistance and lead wire resistance is significant compared with the resistance of the highly conductive specimen. However the resistance of specimens in our study is significantly higher than this threshold.

The geometry of the specimens is shown in Figure 6 where $l$ refers to the length of the copper electrode in contact with the specimen and $w$ the distance between parallel electrodes. $L$ and $T$ denote the longitudinal and transverse directions of the $\mathrm{CF}$, respectively. The nominal values of these parameters for the two specimen types (Figure 6) were $l_{L}=25 \mathrm{~mm}, w_{L}=40 \mathrm{~mm}$, and $l_{T}=$ $50 \mathrm{~mm}$, and $w_{T}=10 \mathrm{~mm}$.

[Figure 6 about here.] 
The measurement of the conductance along a given direction $i$ (with $i=$ $L, T), G_{i}$, allows for the determination of the conductivity, $\sigma_{i}$ :

$$
\sigma_{i}=\frac{G_{i} w_{i}}{t l_{i}}
$$

where $t$ is the thickness of the specimen. As a measure of the electrical anisotropy, the following dimensionless parameter is used:

$$
\lambda=\frac{\sigma_{L}}{\sigma_{T}}
$$

Since carbon fibres are conductive, $\sigma_{L}>>\sigma_{T}$, for a UD composite the parameter $\lambda$ will always be much greater than unity $(\lambda>>1)$, and it will tend to 1 for the case of isotropic electrical material.

\section{Results and discussion}

\subsection{Preliminary results on the conductance of the dry fibre}

The effect of the pyrolysis and CNT CVD processes on the electrical resistance of the thin-ply CF tape was evaluated directly in the dry state before and after treatment. This was to facilitate development of a consistent methodology and material, and identify the level of CNT growth needed to give the most conductive tapes which were then incorporated into epoxy and PP laminates.

The transverse electrical conductance of the tape after pyrolysis (UTS50SPy) was $6.0 \mathrm{mS}$ with a standard deviation of $25 \%$ (Figure 7). This relatively large variability arises from narrow gaps between the fibres that open and close as the sample is manually handled and would diminish with automation. The transverse conductance measured on three batches of UTS50S/CNT is an average of $174 \mathrm{mS}$ which is equivalent to an increase of $\approx 2800 \%$. Although very small in absolute terms, the \% variability of and between batches is slightly lower $(15 \%)$ reflecting the fact that the presence of CNTs has reduced the significance of the gaps between the fibres by providing additional or softer, more conformal contacts.

[Figure 7 about here.] 
SEM analysis (Figure 8) shows that insufficient catalyst treatment results in patchy CNT growth (Figure 8(a) and consequently higher resistance (Figure 9) which is reduced with a uniform CNT layer (Figures 8(b) and 9). The CNT length varies with reaction time such that, with uniform catalyst coating, 10 minutes of growth produces a CNT layer of approximately $1 \mu \mathrm{m}$ (Figure 6b) and 12 minutes of $2 \mu \mathrm{m}$ (Figure $8(\mathrm{c})$ with the heavier growth also producing a lower resistance (Figure 9).

[Figure 8 about here.]

The electrical conductance increases by $100 \%$ (110 mS to $220 \mathrm{mS}$ ) when the reaction time is increased from 10 to 12 minutes, however although a longer reaction time (eg. to $15 \mathrm{~min}$ ) dramatically increases CNT growth (Figure 8(c)], it severely disrupts the tape structure without producing any significant increment in conductance. By weighing the fibre before and after the CVD process it was concluded that the average content of CNTs ranged between the 10 and $30 \mathrm{wt} \%$.

[Figure 9 about here.]

\subsection{Conductivity of Thin-Ply-CNT / IN2 Epoxy System}

Composite specimens were manufactured with IN2 epoxy resin infusion using the pristine thin-ply tape (UTS50S/IN2), tape after pyrolysis (UTS50S$\mathrm{Py} / \mathrm{IN} 2$ ), and tape after 12 minutes of CNT growth (UTS50S/CNT/IN2).

Two unidirectional tape plies (i.e. $[0]_{2}$ ) were used for each specimen to reduce the variability due to manual handling and to make the samples more manageable. The IN2 epoxy composites of the pristine tape are uniformly 0.10 $\mathrm{mm}$ in thickness. The transverse conductance is $3.4 \mathrm{mS}$ with a standard deviation of $8.8 \%$ (Table 1). As the samples are symmetric with respect to fibre and copper contact orientation, the conductivity can be calculated directly from the conductance and sample dimensions [29] and hence is also tabulated.

Pyrolysis of the thin-ply tape increases the conductance of the IN2 samples by about $24 \%$ to $4.2 \mathrm{mS}$ although the standard deviation is increased to about 
15\%. However growth of CNT on the tape increased the conductance 19.5 fold to $66.2 \mathrm{mS}$ compared with the pristine material, and 15.8 fold compared to the pyrolyzed tape (Table 1). Specimens with CNTs are, on average, 2.5 times thicker than the pristine thin-ply as a consequence of the resin entrained by the nanotubes, this difference being taken into account when calculating the sample conductivity (Table 1). The emphasis in this study was to ensure that the specimens were fully penetrated with resin, as the CNTs present an impediment to flow, hence the resin is present in considerable excess. Nevertheless, even taking this difference into account, the conductivity of the CNT-loaded thin-ply was $57.3 \mathrm{~S} / \mathrm{m}$ or 7.5 times higher than the pristine thin-ply. If, as anticipated, the final thickness of the CNT-loaded thin-ply, within an optimised manufactured structure, is essentially that of the pristine ply, the conductivity would be 145 $\mathrm{S} / \mathrm{m}$ and a 19 fold increase in conductivity would have been achieved.

[Table 1 about here.]

\subsection{Conductivity of Thin-Ply-CNT / Polypropylene System}

As with the IN2 epoxy system, composite specimens were manufactured with polypropylene film using two plies of pristine thin-ply tape (UTS50S/PP), pyrolyzed tape (UTS50S-Py/PP), and tape after 12 minutes of CNT growth (UTS50S/CNT/PP). The thickness and transverse resistance were measured and transverse conductivity and conductance calculated (Table 2).

The PP samples show only a slight increase in thickness as a consequence of the CNT loading, supporting the view that the IN2 epoxy system would also be largely unchanged in thickness with the inclusion of CF-grown CNT if resin loading is optimised. The pristine tape PP sample has an average conductance of $4.9 \mathrm{mS}$, fairly comparable to the value of $3.4 \mathrm{mS}$ for the IN2 analogue. However the PP sample is more variable (SD 24\%) due to slight random parting of carbon fibres during pressing. The PP sample with pyrolyzed thin-ply tape produces a $41 \%$ increase in conductance (to $6.9 \mathrm{mS}$ ) compared with pristine tape, although with similar variability. 
Inclusion of CNT modified thin-ply however results in a conductance of 142.9 $\mathrm{mS}$ or 29 times higher than the pristine tape. For the conductivity, where sample thickness is taken into account, the thin-ply-CNT / PP conductivity $(196.5 \mathrm{~S} / \mathrm{m})$ is still 28 times that of the pristine thin-ply sample $(7.1 \mathrm{~S} / \mathrm{m})$. Moreover, the CNT modified sample has an SD of just $9.8 \%$ indicating that the CNTs either resist gap formation or are continuing to bridge any gaps developing between fibres during pressing.

\section{[Table 2 about here.]}

\subsection{Electrical anisotropy}

The main objective of this work concerns the transverse electrical conductivity of thin-ply carbon fibre and its change when CNTs are included. However, electrical properties in the longitudinal CF direction are also of relevance. It was observed that the introduction of CNTs does not influence the longitudinal electrical conductance which, at $500 \mathrm{mS}$ was the same for all samples regardless of processing. Due to the variation in sample thickness however, the longitudinal conductivity ranged from $8 \mathrm{kS} / \mathrm{m}$ for the thinnest (IN2) samples with pristine thin-ply to $3.2 \mathrm{kS} / \mathrm{m}$ for the thickest (thin-ply-CNT /IN2), although appropriate processing is anticipated to improve this substantially. The conductivity of the PP analogues varies only slightly $(5.0 \mathrm{kS} / \mathrm{m}$ to $5.5 \mathrm{kS} / \mathrm{m})$ as the samples do not change greatly in thickness. In terms of the ratio of longitudinal to transverse conductivity or anisotropy factor, $\lambda$, the introduction of CNTs reduces the difference in lateral and transverse conductivity , $\lambda$, from 1000 to just 55.8 for IN2 and from over 750 to only 25.5 for PP (Table 3). This major reduction in anisotropy is anticipated to also be manifested in the through-thickness direction and brings the creation of fully electrically isotropic carbon fibre laminates significantly closer.

[Table 3 about here.] 


\section{Conclusions}

A process to grow uniform, high quality, aligned carbon nanotubes (CNTs) directly on thin-ply carbon fibre $(\mathrm{CF})$ unidirectional tape was developed. This entailed methodologies to handle the tape, strip the binder and sizing, coat with catalyst and grow the CNTs by CVD without significantly disrupting the alignment of the CF whilst achieving an optimum CNT length for enhancing transverse conductivity. Methodologies were also developed to reproducibly incorporate the Thin-Ply-CNT tapes into thermoset and thermoplastic composites. Compared to pristine thin-ply, enhancement with directly grown CNTs increased the transverse conductance 20 and 30 fold in the epoxy and polypropylene composite materials, respectively. Conductivity of these composites was moderated by the increased sample thickness, particularly for the epoxy material, although it is anticipated that optimisation of fabrication will mitigate this issue.

Although the increase in electrical conductivity is at least one order of magnitude more than what is reported in literature for conventional laminates, the level of conductivity obtained is still not sufficient to provide alone an adequate LSP [7, 30] however it would substantially augment existing LSP technologies and form the basis for further improvements. The higher electrical conductivity could also be used to improve the shielding effectiveness (SE) and the ElectroStatic Discharge (ESD) efficiency, and can also help to mitigate the effects of edge glow or thermal hot spots (due also to the consequent increase of transverse thermal conductivity that is not investigated here).

The significant enhancement in transverse conductivity does not influence the longitudinal conductivity and hence the electrical anisotropy of the thin plies is drastically reduced. This improved transverse conductivity is anticipated to be reproduced in the through-thickness direction bringing fully electrically isotropic highly conductive carbon fibre reinforced polymer composites, considerably closer. 


\section{Acknowledgements}

The authors would like to acknowledge financial support from the EPSRC project MACANTA - Multifunctional hierarchical advanced composite aerostructures utilising the combined properties of different carbon nanotube (CNT) assemblies (EP/N007190/1). The first and third authors would also like to acknowledge Prof. Giuseppe Pitarresi of the University of Palermo, and the financial support provided by the Collegio Universitario ARCES through the Erasmus+ mobility grant.

\section{References}

[1] Sangwook Sihn, Ran Y. Kim, Kazumasa Kawabe, and Stephen W. Tsai. Experimental studies of thin-ply laminated composites. Composites Science and Technology, 67(6):996 - 1008, 2007.

[2] Yasuhiro Nishikawa, Kazuya Okubo, Toru Fujii, and Kazumasa Kawabe. Fatigue crack constraint in plain-woven cfrp using newly-developed spread tows. International Journal of Fatigue, 28(10):1248 - 1253, 2006. The Third International Conference on Fatigue of Composites.

[3] Tomohiro Yokozeki, Yuichiro Aoki, and Toshio Ogasawara. Experimental characterization of strength and damage resistance properties of thin-ply carbon fiber/toughened epoxy laminates. Composite Structures, 82(3):382 $-389,2008$.

[4] A. Arteiro, G. Catalanotti, J. Xavier, and P.P. Camanho. Notched response of non-crimp fabric thin-ply laminates. Composites Science and Technology, 79(Supplement C):97 - 114, 2013.

[5] R. Amacher, J. Cugnoni, J. Botsis, L. Sorensen, W. Smith, and C. Dransfeld. Thin ply composites: Experimental characterization and modeling of size-effects. Composites Science and Technology, 101(Supplement C):121 $132,2014$. 
[6] C. Furtado, A. Arteiro, G. Catalanotti, J. Xavier, and P.P. Camanho. Selective ply-level hybridisation for improved notched response of composite laminates. Composite Structures, 145(Supplement C):1 - 14, 2016.

[7] C. Karch and C. Metzner. Lightning protection of carbon fibre reinforced plastics - an overview -. In 2016 33rd International Conference on Lightning Protection (ICLP), pages 1-8, Sept 2016.

[8] Prabhakar R. Bandaru. Electrical Properties and Applications of Carbon Nanotube Structures. Journal of Nanoscience and Nanotechnology, 7(4):1239-1267, 2007.

[9] Wolfgang Bauhofer and Josef Z. Kovacs. A review and analysis of electrical percolation in carbon nanotube polymer composites. Composites Science and Technology, 69(10):1486-1498, 2009.

[10] M. S P Shaffer and A. H. Windle. Analogies between polymer solutions and carbon nanotube dispersions. Macromolecules, 32(20):6864-6866, 1999.

[11] Ian A. Kinloch, Simon A. Roberts, and Alan H. Windle. A rheological study of concentrated aqueous nanotube dispersions. Polymer, 43(26):7483-7491, 2002 .

[12] Vahid Mirjalili, Mostafa Yourdkhani, and Pascal Hubert. Dispersion stability in carbon nanotube modified polymers and its effect on the fracture toughness. Nanotechnology, 23:315701, 2012.

[13] Xiaodong He, Fuhua Zhang, Rongguo Wang, and Wenbo Liu. Preparation of a carbon nanotube/carbon fiber multi-scale reinforcement by grafting multi-walled carbon nanotubes onto the fibers. Carbon, 45(13):2559-2563, 2007.

[14] Abdelghani Laachachi, Alexandre Vivet, Gérard Nouet, Bessem Ben Doudou, Christophe Poilâne, Jun Chen, Jin Bo bai, and M'Hamed Ayachi. A chemical method to graft carbon nanotubes onto a carbon fiber. Materials Letters, 62(3):394-397, 2008. 
[15] Fu Hua Zhang, Rong Guo Wang, Xiao Dong He, Chao Wang, and Li Ning Ren. Interfacial shearing strength and reinforcing mechanisms of an epoxy composite reinforced using a carbon nanotube/carbon fiber hybrid. Journal of Materials Science, 44(13):3574-3577, 2009.

[16] E. Bekyarova, E. T. Thostenson, A. Yu, H. Kim, J. Gao, J. Tang, H. T. Hahn, T.-W. Chou, M. E. Itkis, and R. C. Haddon. Multiscale Carbon NanotubeCarbon Fiber Reinforcement for Advanced Epoxy Composites. Langmuir, 23(7):3970-3974, mar 2007.

[17] Alejandro J. Rodriguez, Mauricio E. Guzman, Chee Sern Lim, and Bob Minaie. Mechanical properties of carbon nanofiber/fiber-reinforced hierarchical polymer composites manufactured with multiscale-reinforcement fabrics. Carbon, 49(3):937-948, 2011.

[18] Jinhai Guo, Chunxiang Lu, Feng An, and Shuqing He. Preparation and characterization of carbon nanotubes/carbon fiber hybrid material by ultrasonically assisted electrophoretic deposition. Materials Letters, 66(1):382$384,2012$.

[19] Naveed A. Siddiqui, Man Lung Sham, Ben Zhong Tang, Arshad Munir, and Jang Kyo Kim. Tensile strength of glass fibres with carbon nanotubeepoxy nanocomposite coating. Composites Part A: Applied Science and Manufacturing, 40(10):1606-1614, 2009.

[20] Zhi-hui Hu, Shao-ming Dong, Jian-bao Hu, Zhen Wang, Bo Lu, Jin-shan Yang, Qing-gang Li, Bin Wu, Le Gao, and Xiang-yu Zhang. Synthesis of carbon nanotubes on carbon fibers by modified chemical vapor deposition. New Carbon Materials, 27(5):352-361, 2012.

[21] S. Rahmanian, A. R. Suraya, R. Zahari, and E. S. Zainudin. Synthesis of vertically aligned carbon nanotubes on carbon fiber. Applied Surface Science, 271:424-428, 2013. 
[22] Brian G. Falzon, Stephen C. Hawkins, Chi P. Huynh, Racim Radjef, and Callum Brown. An investigation of mode i and mode ii fracture toughness enhancement using aligned carbon nanotubes forests at the crack interface. Composite Structures, 106:65 - 73, 2013.

[23] T. R. Pozegic, I. Hamerton, J. V. Anguita, W. Tang, P. Ballocchi, P. Jenkins, and S. R.P. Silva. Low temperature growth of carbon nanotubes on carbon fibre to create a highly networked fuzzy fibre reinforced composite with superior electrical conductivity. Carbon, 74:319-328, 2014.

[24] Yong Chul Shin, Eliah Novin, and Hansang Kim. Electrical and thermal conductivities of carbon fiber composites with high concentrations of carbon nanotubes. International Journal of Precision Engineering and Manufacturing, 16(3):465-470, 2015.

[25] T. R. Pozegic, J. V. Anguita, I. Hamerton, K. D. G. I. Jayawardena, J-S. Chen, V. Stolojan, P. Ballocchi, R. Walsh, and S. R. P. Silva. MultiFunctional Carbon Fibre Composites using Carbon Nanotubes as an Alternative to Polymer Sizing. Scientific Reports, 6(1):37334, dec 2016.

[26] T. R. Pozegic, K. D.G.I. Jayawardena, J. S. Chen, J. V. Anguita, P. Ballocchi, V. Stolojan, S. R.P. Silva, and I. Hamerton. Development of sizing-free multi-functional carbon fibre nanocomposites. Composites Part A: Applied Science and Manufacturing, 90:306-319, 2016.

[27] Johannes Rehbein, Peter Wierach, Thomas Gries, and Martin Wiedemann. Improved electrical conductivity of NCF-reinforced CFRP for higher damage resistance to lightning strike. Composites Part A: Applied Science and Manufacturing, 100:352-360, sep 2017.

[28] Stephen C. Hawkins, Jacinta M. Poole, and Chi P. Huynh. Catalyst distribution and carbon nanotube morphology in multilayer forests by mixed cvd processes. The Journal of Physical Chemistry C, 113(30):12976-12982, 2009. 
[29] X. Yao, B.G. Falzon, S.C. Hawkins, and S. Tsantzalis. Aligned carbon nanotube webs embedded in a composite laminate: A route towards a highly tunable electro-thermal system. Carbon, 129:486 - 494, 2018.

[30] M. Gagné and D. Therriault. Lightning strike protection of composites. Progress in Aerospace Sciences, 64:1-16, January 2014. 
Table 1: Electrical measurements for the IN2 composites.

\begin{tabular}{|c|c|c|c|c|}
\hline Material system & S Specimen label & $\begin{array}{c}\text { Thickness, } t \\
(\mathrm{~mm})\end{array}$ & $\begin{array}{l}\text { Transverse conductance, } G_{T} \\
(\mathrm{mS})\end{array}$ & $\begin{array}{c}\text { Conductivity, } \sigma_{T} \\
(\mathrm{~S} / \mathrm{m})\end{array}$ \\
\hline \multirow{5}{*}{ UTS50S/IN2 } & 1 & 0.10 & 3.8 & 8.3 \\
\hline & 2 & 0.10 & 3.4 & 7.4 \\
\hline & 3 & 0.10 & 3.2 & 7.0 \\
\hline & Ave. & 0.10 & 3.4 & 7.6 \\
\hline & STDEV & 0 & 0.3 & 0.7 \\
\hline \multirow{8}{*}{ UTS50S-Py/IN2 } & 1 & 0.16 & 3.6 & 4.9 \\
\hline & 2 & 0.14 & 4.5 & 7.1 \\
\hline & 3 & 0.13 & 5.1 & 8.5 \\
\hline & 4 & 0.12 & 4.4 & 8.1 \\
\hline & 5 & 0.12 & 3.8 & 7.1 \\
\hline & 6 & 0.12 & 3.4 & 6.3 \\
\hline & Ave. & 0.13 & 4.2 & 7.0 \\
\hline & STDEV & 0.02 & 0.6 & 1.3 \\
\hline \multirow{6}{*}{ UTS50S/CNT/IN2 } & 1 & 0.25 & 70.9 & 62.4 \\
\hline & 2 & 0.27 & 61.3 & 50.0 \\
\hline & 3 & 0.25 & 56.8 & 50.0 \\
\hline & 4 & 0.25 & 75.8 & 66.7 \\
\hline & Ave. & 0.26 & 66.2 & 57.3 \\
\hline & STDEV & 0.01 & 8.7 & 8.6 \\
\hline
\end{tabular}


Table 2: Electrical measurements for the PP composites.

\begin{tabular}{|c|c|c|c|c|}
\hline Material system & Specimen label & $\begin{array}{l}\text { Thickness, } t \\
\text { (mm) }\end{array}$ & $\begin{array}{c}\text { Transverse conductance, } G_{T} \\
(\mathrm{mS})\end{array}$ & $\begin{array}{c}\text { Conductivity, } \sigma_{T} \\
(\mathrm{~S} / \mathrm{m})\end{array}$ \\
\hline \multirow{6}{*}{ UTS50S/PP } & 1 & 0.15 & 4.4 & 6.5 \\
\hline & 2 & 0.15 & 6.4 & 9.4 \\
\hline & 3 & 0.15 & 5.0 & 7.3 \\
\hline & 4 & 0.15 & 3.6 & 5.3 \\
\hline & Ave. & 0.15 & 4.9 & 7.1 \\
\hline & STDEV & 0 & 1.2 & 1.7 \\
\hline \multirow{6}{*}{ UTS50S-Py/PP } & 1 & 0.15 & 5.7 & 8.4 \\
\hline & 2 & 0.15 & 9.2 & 13.5 \\
\hline & 3 & 0.15 & 6.0 & 8.8 \\
\hline & 4 & 0.15 & 6.5 & 9.5 \\
\hline & Ave. & 0.15 & 6.9 & 10.1 \\
\hline & STDEV & 0 & 1.6 & 2.3 \\
\hline \multirow{6}{*}{ UTS50S/CNT/PP } & 1 & 0.16 & 125.0 & 171.9 \\
\hline & 2 & 0.16 & 158.7 & 218.3 \\
\hline & 3 & 0.16 & 147.1 & 202.2 \\
\hline & 4 & 0.16 & 140.8 & 193.7 \\
\hline & Ave. & 0.16 & 142.9 & 196.5 \\
\hline & STDEV & 0 & 14.1 & 19.3 \\
\hline
\end{tabular}

Table 3: Salient electrical parameters for the material system investigated.

\begin{tabular}{cccc}
\hline Material system & $\begin{array}{c}\text { Transverse conductivity, } \sigma_{T} \\
(\mathrm{~S} / \mathrm{m})\end{array}$ & $\begin{array}{c}\text { Longitudinal conductivity, } \sigma_{L} \\
(\mathrm{~S} / \mathrm{m})\end{array}$ & $\begin{array}{c}\lambda \\
(-)\end{array}$ \\
\hline UTS50S/IN2 & 7.6 & 8000 & 1052.6 \\
UTS50S/CNT/IN2 & 57.3 & 3200 & 55.8 \\
\hline UTS50S/PP & 7.1 & 5333 & 751.2 \\
UTS50S/CNT/PP & 196.5 & 5000 & 25.5 \\
\hline \hline
\end{tabular}




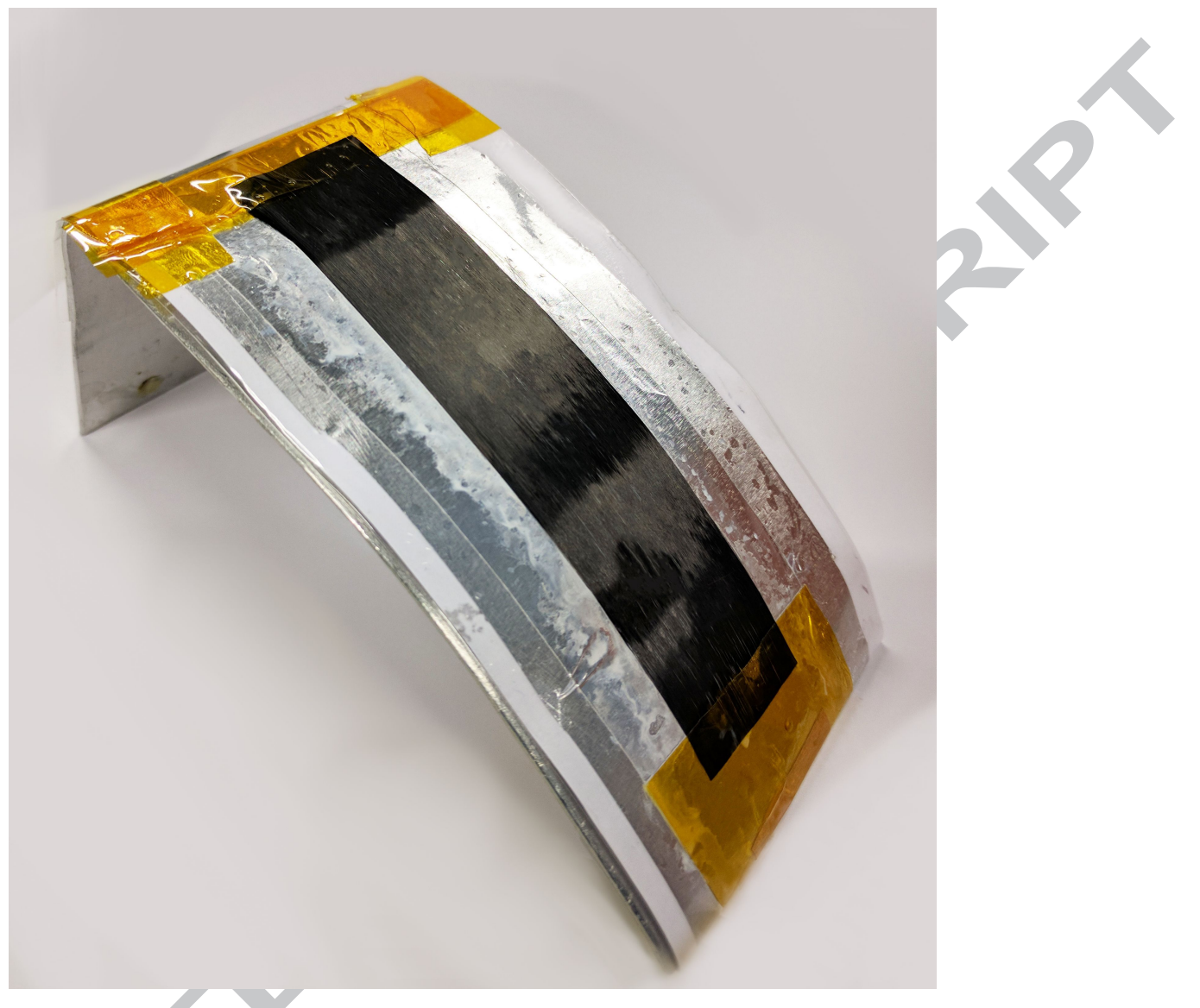

Figure 1: Fibre tape mounted on curved frame 


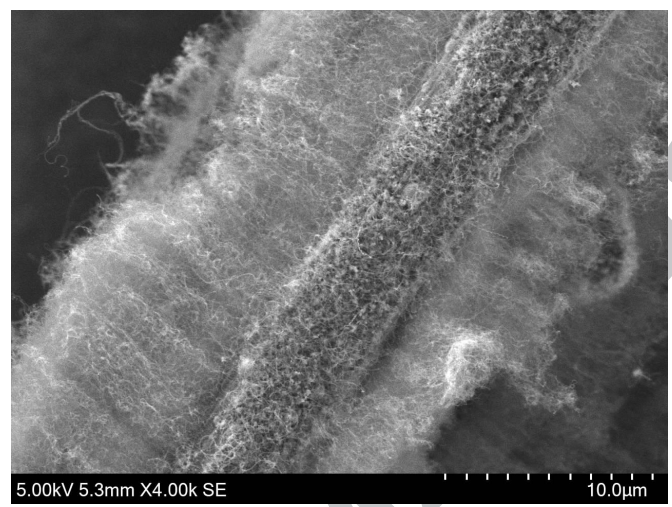

(a) Aligned CNTs forest on a carbon fibre.
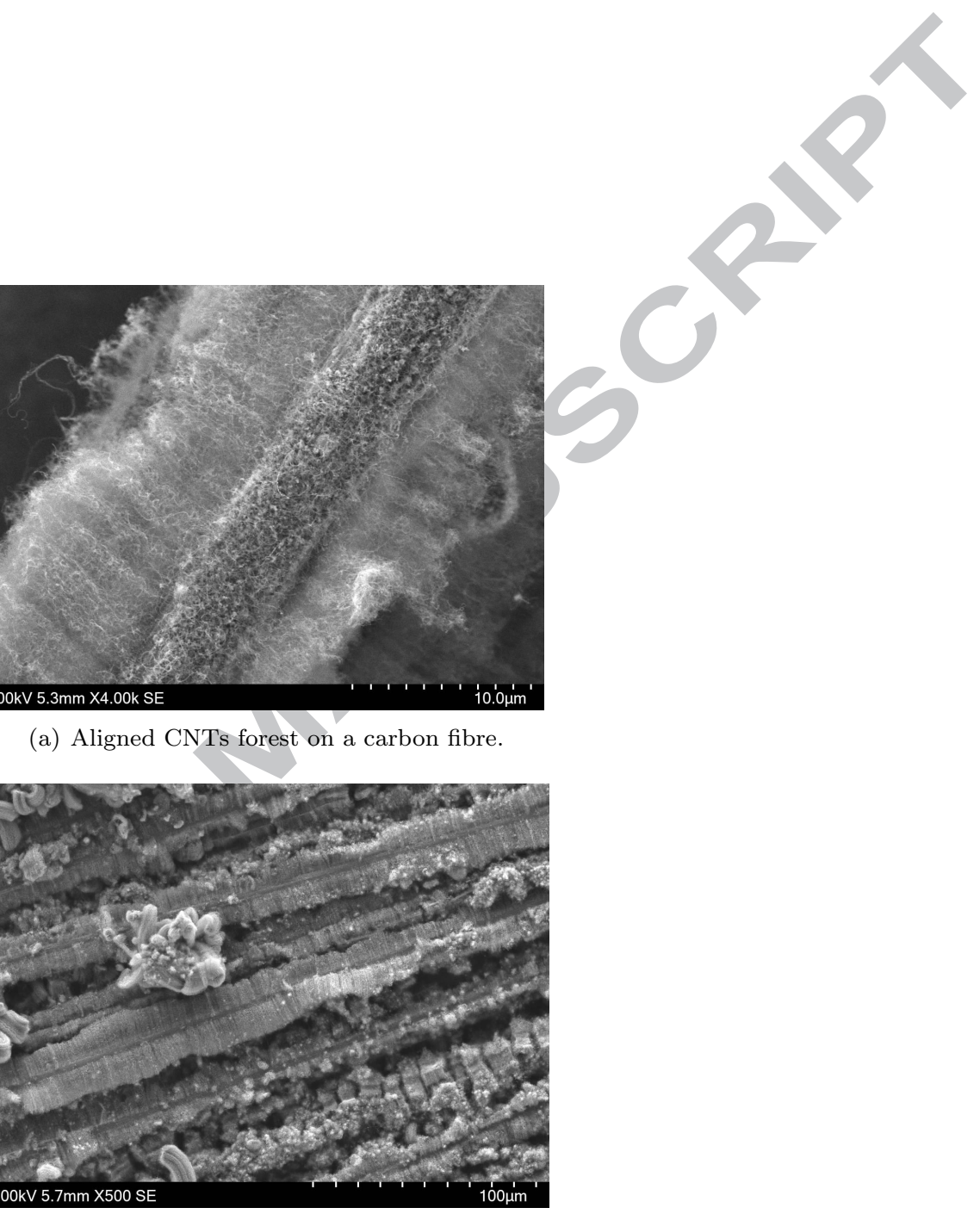

(b) Different CNT structures.

Figure 2: CNT structures for a reaction time of over $15 \mathrm{~min}$. 


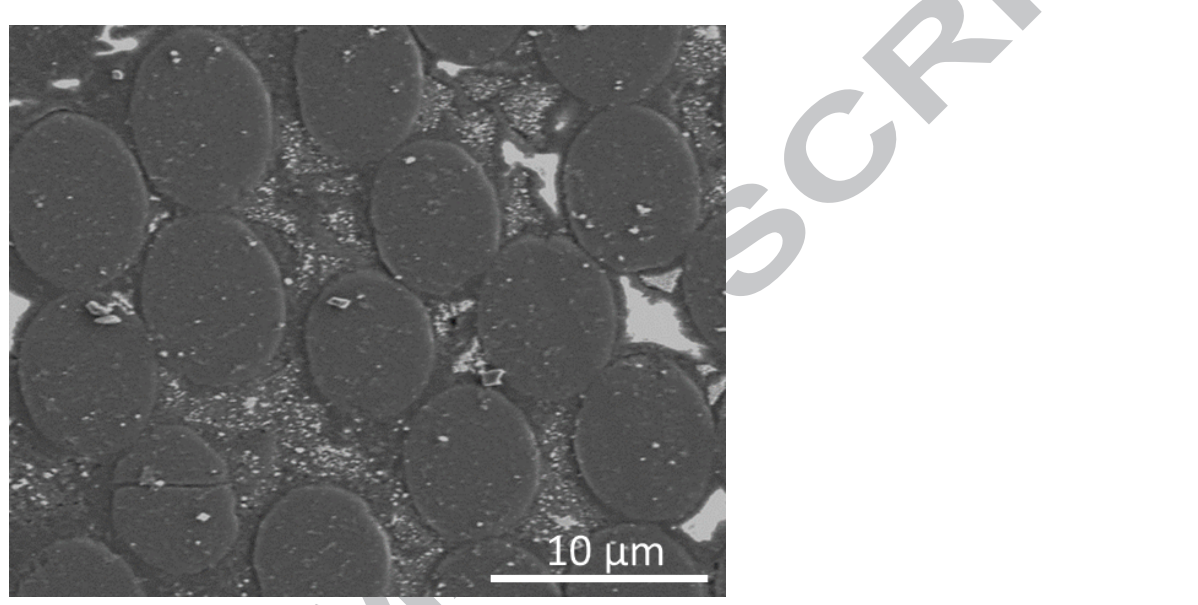

(a) $3.00 \mathrm{k}$ magnification.

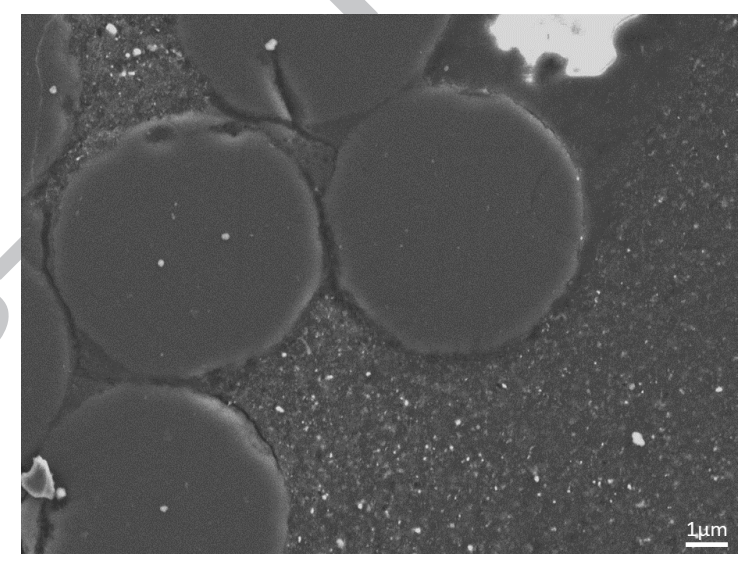

(b) $7.00 \mathrm{k}$ magnification.

Figure 3: SEM images of the transverse cross section of the UTS50S/CNT/IN2 laminate. 


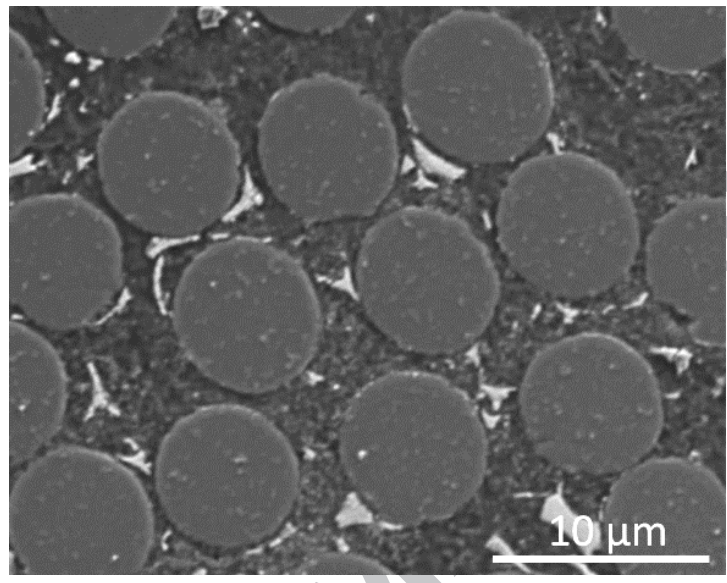

(a) $3.00 \mathrm{k}$ magnification.

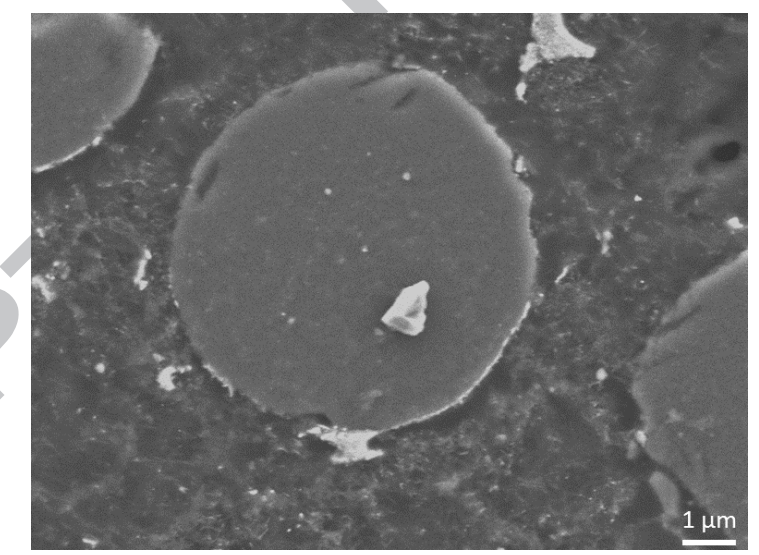

(b) $7.00 \mathrm{k}$ magnification.

Figure 4: SEM images of the transverse cross section of the UTS50S/CNT/PP laminate. 


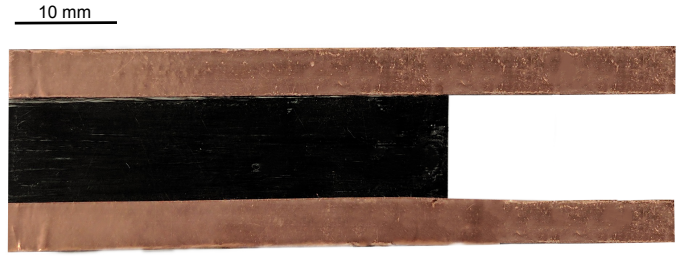

(a) UTS50S/IN2.

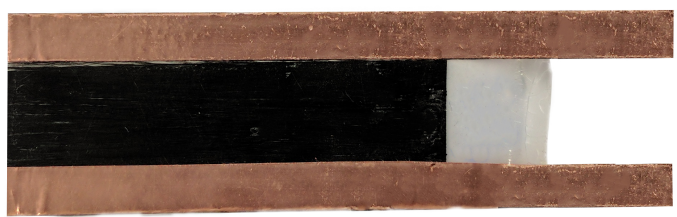

(b) UTS50S/PP

Figure 5: Test laminates after curing (for measuring the transverse resistance, $R_{T}$ ).

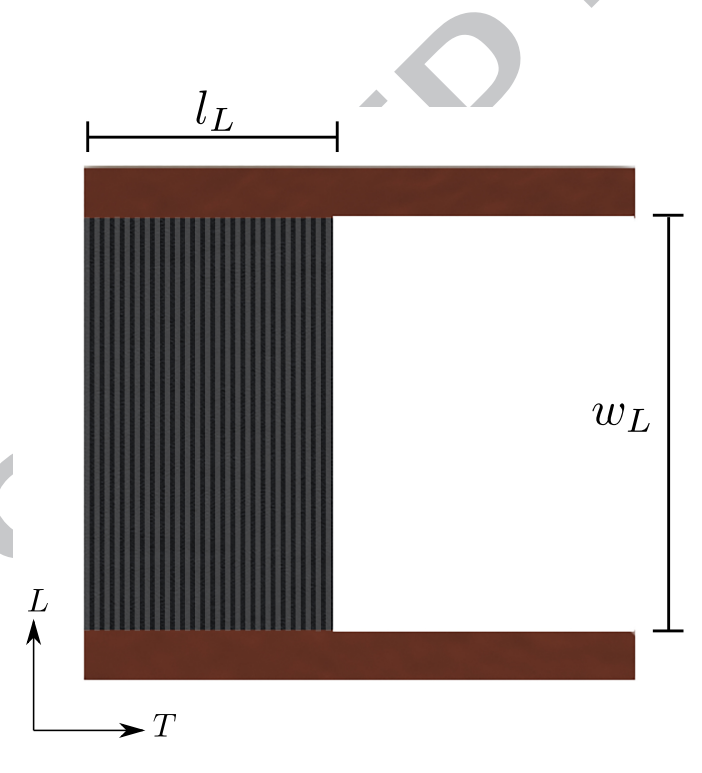

(a) Longitudinal conductivity.

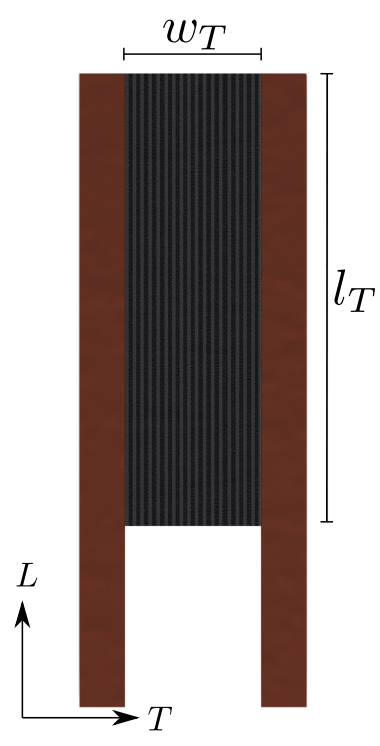

(b) Transverse conductivity.

Figure 6: Geometry of the specimens used for the electrical measurements. 

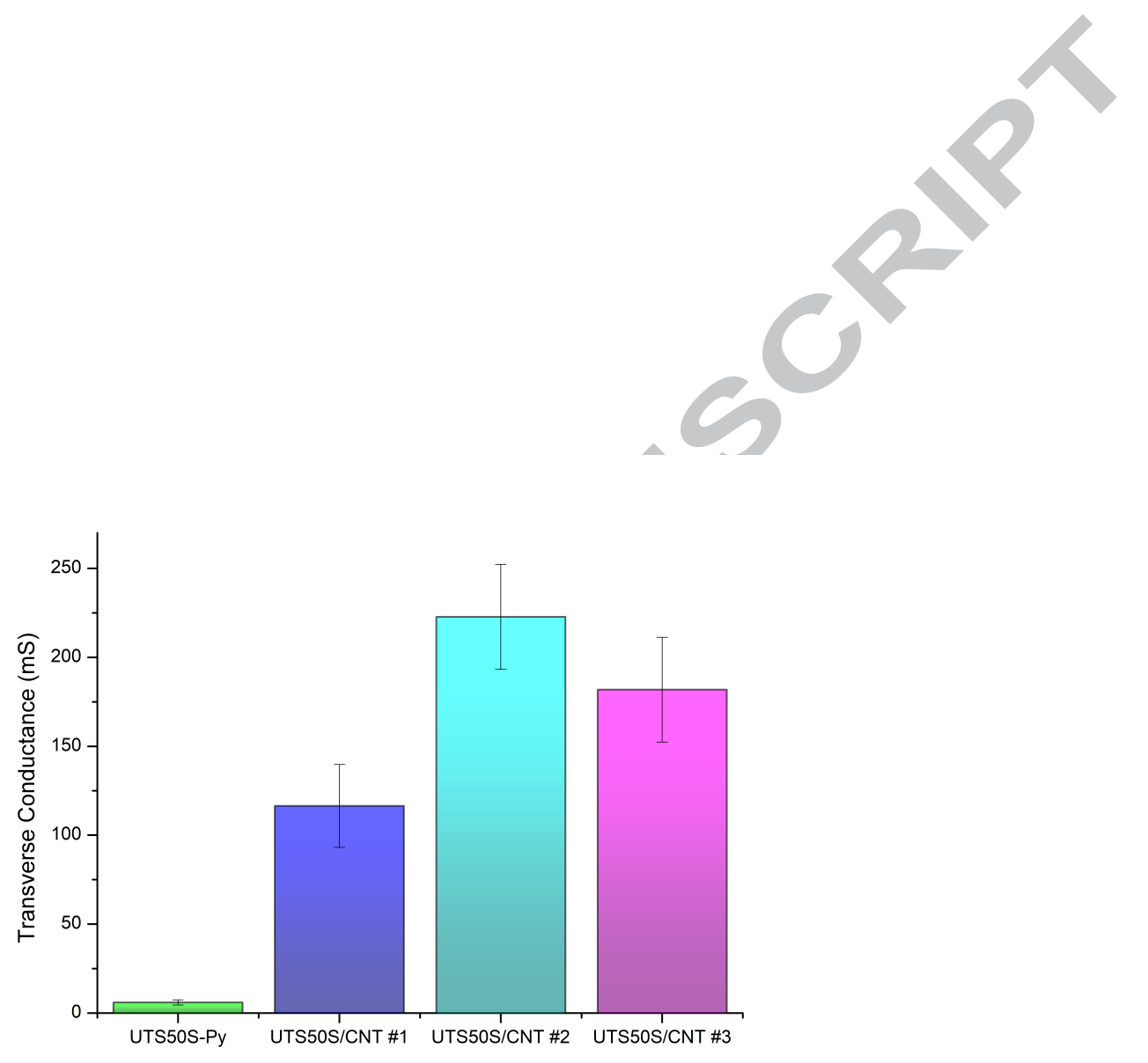

Figure 7: Transverse conductance of the fibres before lamination. 

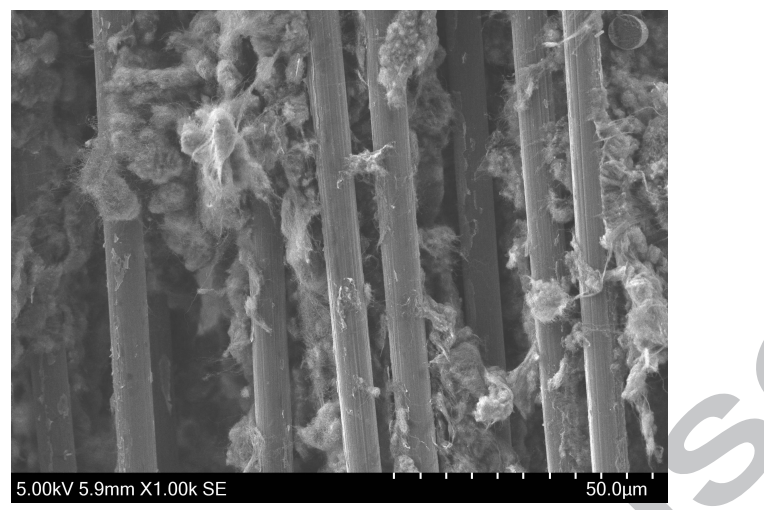

(a) Inhomogeneous distribution of CNTs.

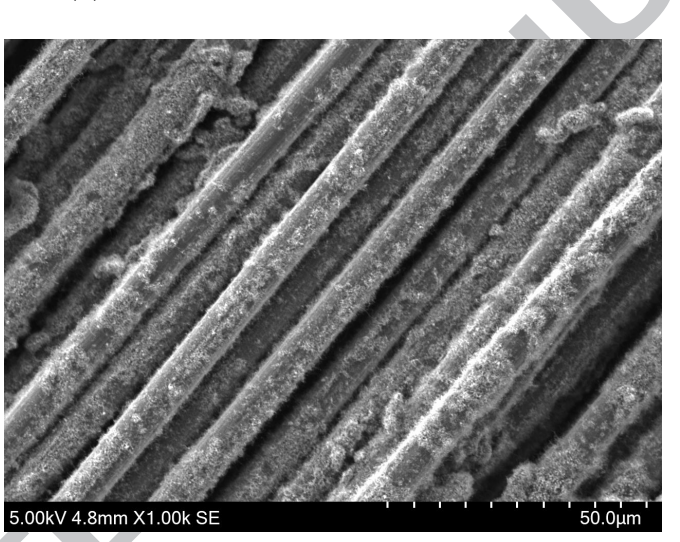

(b) Reaction time of $t_{r}=10 \mathrm{~min}$.

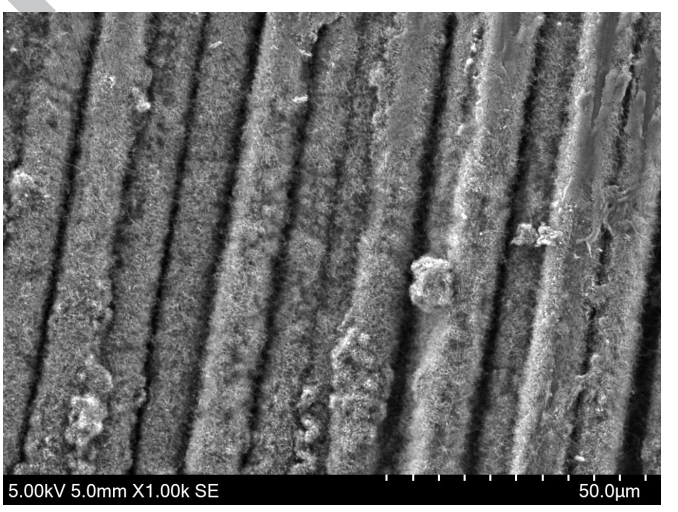

(c) Reaction time of $t_{r}=12 \mathrm{~min}$.

Figure 8: Morphology of CNTs as a function of the reaction time. 

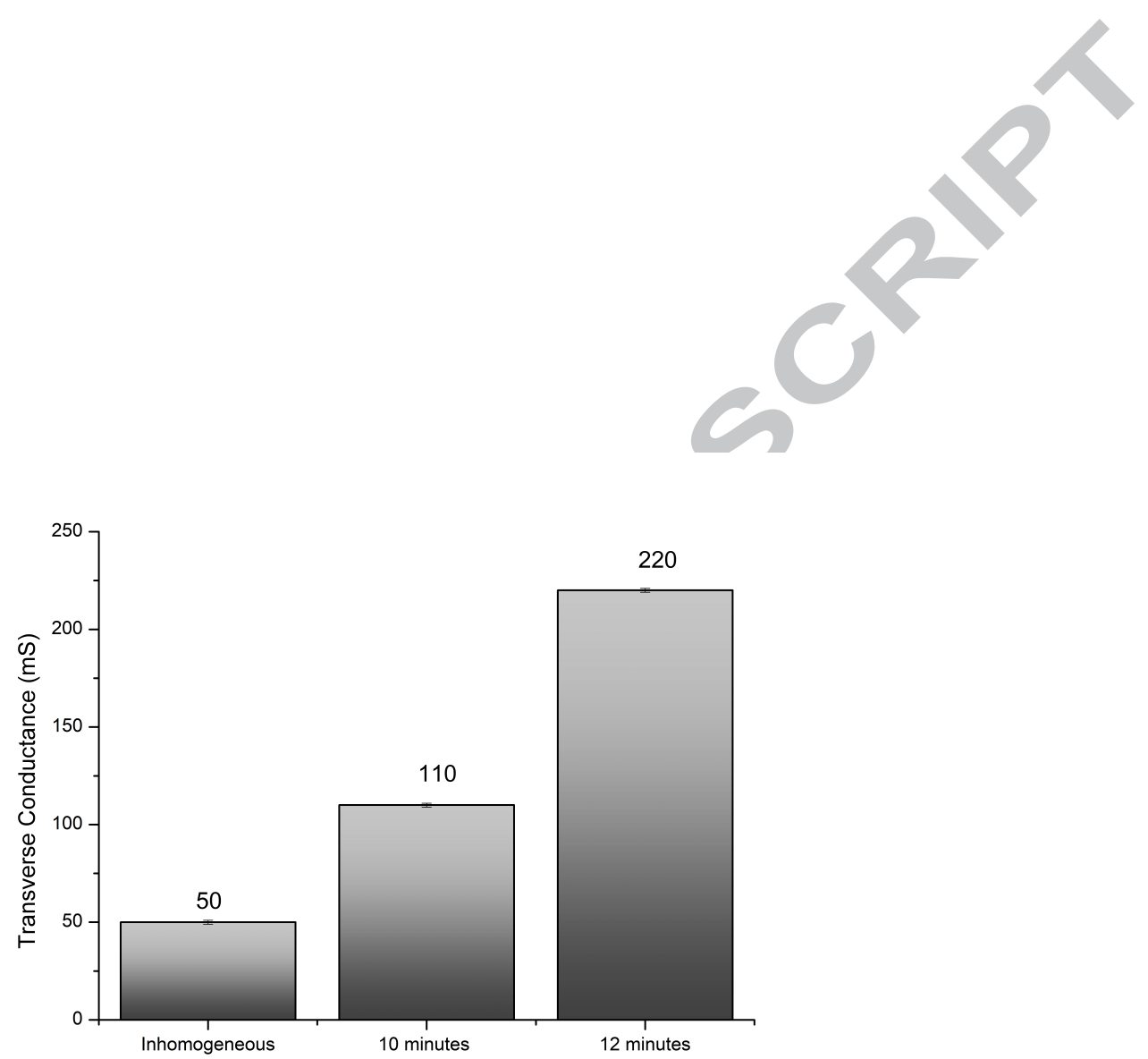

Figure 9: Transverse conductance of dry carbon fibre thin-ply measured for patchy distribution of CNTs, and uniform CNT coating for a reaction time of 10 and $12 \mathrm{~min}$. 